\title{
CONSULTA PUERPERAL DE ENFERMAGEM: PREVENÇÃO DE COMPLICAÇÕES MAMÁRIAS
}

\author{
Suellen Vienscoski Skupien ${ }^{1}$, Ana Paula Xavier Ravelli², Laura Vargas Acauan ${ }^{3}$
}

RESUMO: Objetivou-se identificar os problemas mamários de puérperas atendidas em uma maternidade escola no município de Ponta Grossa, Paraná. Pesquisa exploratória quantitativa a partir da coleta de dados no período de março a novembro de 2015. A partir dos resultados, foi possível identificar o perfil obstétrico das puérperas, problemas mamários como a fissura mamilar, ingurgitamento e mastite. Concluiu-se que o Projeto Consulta de Enfermagem no Pré-Natal e Pós-Parto oportunizou a descoberta de problemas mamários relevantes, trazendo subsídios para prevenir as complicações mamárias por meio da educação em saúde no pós-parto.

DESCRITORES: Aleitamento materno; Período pós-parto; Educação em saúde; Enfermagem.

\section{POSTPARTUM NURSING CONSULTATIONS: PREVENTION OF BREAST COMPLICATIONS}

ABSTRACT: The present study aimed to identify breast disorders of postpartum women admitted to a maternity ward at a teaching hospital in the city of Ponta Grossa, Paraná. Quantitative exploratory study based on data collection performed from March to November 2015. The results obtained allowed to identify the obstetric profile of those women, breast complications such as cracked nipples, engorgement and mastitis. It is concluded that the Prenatal and Postpartum Nursing Consultation Project provided an opportunity to identify important breast complications, through health education in the postpartum period.

DESCRIPTORS: Breastfeeding; Postpartum period; Health education; Nursing.

\section{CONSULTA PUERPERAL DE ENFERMERÍA: PREVENCIÓN DE COMPLICACIONES DE LA MAMA}

RESUMEN: Estudio cuya finalidad fue identificar los problemas de la mama de puérperas en atendimiento de una maternidad escuela en el municipio de Ponta Grossa, Paraná. Investigación exploratoria cuantitativa por medio de datos obtenidos en el periodo de marzo a noviembre de 2015. Con los resultados, fue posible identificar el perfil obstétrico de las puérperas, problemas de mama como la fisura del pezón, congestión y mastitis. Se concluyó que el Proyecto Consulta de Enfermería en el Prenatal y Posparto posibilitó el descubrimiento de problemas mamarios relevantes, fornecendo subsidios para prevenir las complicaciones mamarias por medio de la educación en salud en el posparto.

DESCRIPTORES: Amamantamiento materno; Periodo posparto; Educación en salud; Enfermería.

${ }^{1}$ Enfermeira. Mestre em Tecnologia em Saúde. Docente de Enfermagem e Saúde Pública da Universidade Estadual de Ponta Grossa. Ponta Grossa, PR, Brasil.

${ }^{2}$ Enfermeira Obstétrica. Mestre em Enfermagem. Docente de Enfermagem e Saúde Pública da Universidade Estadual de Ponta Grossa. Ponta Grossa, PR, Brasil.

${ }^{3}$ Enfermeira. Mestre em Enfermagem. Docente de Enfermagem e Saúde Pública da Universidade Estadual de Ponta Grossa. Ponta Grossa, PR, Brasil. 


\section{INTRODUÇÃO}

O puerpério é um período caracterizado pelo recuo gradativo e fisiológico do corpo materno, necessitando de cuidados e informações, como os cuidados na lactação(1). Desta forma, a consulta puerperal de enfermagem visa detectar e avaliar os fatores fisiológicos da puérpera e, principalmente, orientar a prática do aleitamento materno, prevenindo assim as complicações mamárias e o desmame precoce $^{(2)}$.

Nesta perspectiva, o Ministério da Saúde e a Organização Mundial da Saúde preconizam o aleitamento materno exclusivo até os seis meses de vida, justificando os benefícios desta prática na saúde materno-infantil, porém a realidade está distante do preconizado(3).

Pesquisa realizada na região Sul do Brasil(4) sobre aleitamento materno apontou que, no primeiro mês de vida, $60 \%$ das crianças observadas estavam em aleitamento materno exclusivo e 10\% já haviam sido desmamadas. Já no terceiro mês, $29 \%$ haviam sido desmamadas e $39 \%$ recebiam aleitamento materno exclusivo. Em outra pesquisa(5), realizada no município de Londrina, constatou que, das $72,5 \%$ crianças amamentadas na primeira hora de vida, somente 33,8\% continuaram com aleitamento materno exclusivo durante os seis meses seguintes. A média de duração do aleitamento materno exclusivo neste estudo foi de 4 meses e 27 dias. Todavia, essa realidade também permeia em âmbito local e ao indagar o que levam as puérperas a desmamar precocemente seus filhos, é preciso então identificar os fatores determinantes de tal prática. Dentre os inúmeros fatores, destaca-se a falta de informação sobre a função bio-psicológica da amamentação e o despreparo dos profissionais de saúde ${ }^{(6)}$.

Neste contexto, o estado do Paraná, através da Rede Mãe Paranaense ${ }^{(7)}$, definida como prioritária, baseada na análise dos indicadores de mortalidade infantil e materna criada para reduzir ainda mais esses indicadores, amplia as ações de incentivo ao aleitamento materno, dentre outras, e procura garantir o leite humano também para crianças de risco.

Em âmbito nacional, o Ministério da Saúde criou programas e políticas que se articulam com as demais propostas de apoio, promoção e proteção ao aleitamento materno. O Programa Iniciativa Hospital Amigo da Criança ${ }^{(8)}$ é um desses, que objetiva apoiar o aleitamento materno nos hospitais a partir dos "Dez Passos para o Incentivo do Aleitamento Materno", propondo mudanças nas rotinas e condutas.

Outro programa é a Rede Amamenta Brasil(9), também uma iniciativa voltada para o apoio ao aleitamento materno, na atenção primária. Os enfermeiros são capacitados e preparados para fornecer orientação e apoio de qualidade, de forma interativa e crítico reflexiva. Assim, por meio da orientação, a mãe mantém a prática do aleitamento materno, com a pega correta do lactente no mamilo e aréola, prevenindo lesões mamilares e o desmame precoce.

Para que se atinjam os objetivos da Secretaria de Saúde do Paraná e do Ministério da Saúde, salientase a importância da prevenção das lesões mamilares, que podem ser ocasionada principalmente pela pega incorreta do bebê, geralmente na primeira semana de pós-parto. Vale ressaltar que as lesões mamilares são muito dolorosas e podem ser evitadas com educação em saúde, destacando a importância do papel do profissional enfermeiro ${ }^{(10)}$.

Justifica-se este estudo por trazer a possibilidade de prevenção dos danos à saúde da puérpera, uma vez que alguns problemas aos quais a mulher nesse período está sujeita são evitáveis.

Sendo assim, mais estudos são necessários para reforçar a importância da atuação do enfermeiro como educador em saúde a fim de prevenir complicações puerperais realizando ações voltadas para promoção e prevenção à saúde, neste estudo, por acadêmicos e docentes.

Diante do exposto, a hipótese que norteia este estudo: na consulta puerperal de enfermagem podese identificar e prevenir as complicações mamárias em puérperas a partir da educação em saúde. Portanto, esta pesquisa objetiva identificar os problemas mamários de puérperas atendidas em uma maternidade escola na cidade de Ponta Grossa, Paraná. 
Estudo descritivo, exploratório com abordagem quantitativa, realizado em uma maternidade escola de referência ao parto de risco habitual/intermediário do município de Ponta Grossa - Paraná, nos meses de março a novembro de 2015.

Os dados primários são advindos do Projeto de Pesquisa e Extensão Consulta de Enfermagem no Pré-natal e Pós-parto. A população do estudo foi composta por mulheres que vivenciaram o período pós-parto imediato, primeiro ao décimo dia, e que estivessem internadas na maternidade escola, sendo estes os critérios de inclusão. Os critérios de exclusão foram mulheres que estivessem fora do período pós-parto imediato, não estivessem internadas e não concordassem em participar do estudo. Foi utilizada uma amostra por conveniência de 252 puérperas, perfazendo o total geral de participantes.

A coleta de dados se deu por questionário estruturado com 30 perguntas fechadas referentes à identificação; antecedentes ginecológicos, obstétricos e familiares; estado nutricional e gestação atual. Os questionários foram preenchidos por acadêmicos de enfermagem do $4^{\circ}$ ano treinados para esta função, em salas reservadas, no local de estudo, durante a consulta de enfermagem que durou em média 40 minutos. As informações foram digitadas em um banco de dados no Programa EPI INFO, versão 3.3.1. Para a análise dos dados, utilizou-se o software Statistical Package for Social Sciences (SPSS), versão 13.

O projeto foi aprovado pelo Comitê de Ética em Pesquisa da Universidade Estadual de Ponta Grossa, sob o parecer número 1.055.927/2015. A participação no estudo se deu depois do aceite ao convite, a qual foi firmada por meio da assinatura do Termo de Consentimento Livre e Esclarecido. O estudo atendeu às normas nacionais e internacionais de ética em pesquisa envolvendo seres humanos.

\section{RESULTADOS}

Para elucidar o estudo, destaca-se brevemente o perfil obstétrico e sociodemográfico das puérperas, onde 124 (49,1\%) são primigestas e 128 (50,9\%) multigestas. Na avaliação da idade utilizou-se uma categorização em faixas etárias, 134 (53\%) pertenciam à faixa etária de 21 a 30 anos. Com relação ao grau de escolaridade e vínculo empregatício, 68 (27\%) possuem ensino médio completo e 166 (66\%) não possuem vínculo empregatício.

Quanto à realização das consultas de pré-natal, houve 252 (100\%) de adesão da amostra, porém 112 $(44,5 \%)$ realizaram menos de seis consultas de pré-natal e 130 (51,5\%) fizeram seis ou mais consultas, entre as entrevistadas apenas $10(4 \%)$ realizaram nove consultas pré-natais, como recomendado.

Outro dado advindo da consulta de enfermagem foi quanto à participação das puérperas em grupo de gestantes com o profissional enfermeiro, onde 121 (48,1\%) participaram e 131 (51,9\%) não participaram de nenhum grupo no decorrer da gestação. Por sua vez, quando questionadas sobre o recebimento de informações referentes à prática do aleitamento materno, 168 (66,5\%) puérperas afirmaram ter recebido orientações sobre a importância do aleitamento materno para a saúde do bebê nos seis primeiros meses de vida e, especialmente, para o cuidado com as mamas, entretanto 84 (33,5\%) informaram não ter recebido nenhum tipo de orientação em relação à amamentação.

Em relação às complicações mamárias, na consulta de enfermagem evidenciou-se o ingurgitamento mamário, popularmente conhecido como a mama "pedrada", onde 24 (9,2\%) puérperas apresentaram em ambas as mamas.

O aparecimento de fissuras mamilares ocorreu em 135 (53,5\%) puérperas, dessas 59 (23,5\%) tiveram fissuras na mama direita e $76(30 \%)$ na mama esquerda. Quanto às fissuras identificadas na mama direita 59 (23,5\%), 42 (71\%) puérperas apresentaram pequenas fissuras, quatro (8\%) médias, 11 (19\%) grandes e dois (2\%) na forma de vesícula. Já na mama esquerda $76(30 \%), 12$ (16\%) puérperas apresentaram pequenas fissuras, 60 (79\%) médias, três (4\%) grandes e um (1\%) na forma de vesícula. O estudo também revelou que, das $121(48,1 \%)$ puérperas que participaram de grupo de gestantes, 25 (10\%) tiveram fissuras na mama direita, 30 (12\%) na mama esquerda e 66 (26,1\%) afirmaram não sentir nenhum desconforto ao amamentar e também não apresentaram fissuras, reforçando a importância 
da educação em saúde realizada pelo enfermeiro no pré-natal.

Por fim evidenciou-se a mastite, uma inflamação mamária, apresentada por 15 (6\%) puérperas, dessas quatro $(1,6 \%)$ referiram dor e apresentaram sinais de calor/rubor na mama direita e $11(4,4 \%)$ na mama esquerda.

\section{DISCUSSÃO}

Considerada como um ato fisiologicamente básico, a amamentação não é sempre instintiva, precisando ser aprendida e estimulada pelas puérperas. Neste sentido, algumas puérperas mostramse inseguras por não terem tido experiência anterior, o que torna sua participação em atividades educativas que abordem aleitamento materno, onde possam esclarecer suas dúvidas, importante ${ }^{(5)}$. De acordo com os resultados encontrados, a maioria das mulheres entrevistadas não estavam no seu primeiro puerpério, uma vez que eram multíparas em uma faixa etária considerada fisiologicamente ideal para manutenção da gravidez, porém com baixa escolaridade. Sabe-se que o grau de escolaridade pode dificultar o entendimento das puérperas quanto às ações de promoção ao aleitamento materno, influenciando na decisão de continuar ou não a amamentação( ${ }^{(6)}$.

A realização de ações educativas durante o acompanhamento da mulher no ciclo gravídico-puerperal tem grande relevância, devendo ser iniciado o mais precoce possível, almejando menor probabilidade de complicações no puerpério e sucesso na amamentação ${ }^{(11)}$.

Durante o pré-natal, a mulher deverá ser orientada para viver este ciclo de forma positiva, realizando no mínimo seis consultas, uma no primeiro trimestre, duas no segundo e três no último trimestre, além de uma consulta no puerpério, até 42 dias após o parto ${ }^{(11-12)}$. Em relação ao comparecimento nas consultas de pré-natal, o estudo mostrou que houve (100\%) adesão por parte das puérperas, porém ainda é necessário incentivá-las para que compareçam às seis consultas.

Para que o pré-natal seja de qualidade, os profissionais devem ser capacitados permanentemente para realizarem atividades assistenciais concomitantemente com ações educativas, sejam elas individuais ou em grupos, capazes de fazer com que as gestantes conheçam e compreendam todo o processo gestacional. Os grupos tem sido utilizados como estratégia do processo educativo, como espaço de conhecimento, de trocas de experiências, de esclarecimentos, de consolidações de vínculos e espaço terapêutico onde as angústias são compartilhadas ${ }^{(13)}$. Apesar da importância do grupo de gestantes, a maioria das puérperas entrevistadas afirmaram que não participaram de nenhum grupo, mas que receberam informações sobre a prática do aleitamento materno nas consultas de pré-natal.

O pré-natal visa à detecção precoce de alterações na gestante e seu feto, também é o momento propício para o enfermeiro na identificação do conhecimento por parte da gestante referente à prática do aleitamento materno, garantindo seu início e manutenção ${ }^{(7)}$. Neste momento é interessante que a gestante receba informações para que possa preparar suas mamas, a fim de evitar fissuras e complicações mais graves como a mastite, abscessos mamários e retenção láctea ${ }^{(14)}$.

Salienta-se que o enfermeiro tem interferido positivamente na amamentação através das orientações repassadas no pré-natal, porém temos resistência por parte das gestantes, já que muitas não comparecem às seis consultas, preconizadas pelo Ministério da Saúde ${ }^{(11)}$.

Os profissionais da saúde tem papel fundamental em tornar a amamentação um ato de prazer, garantindo à puérpera o esclarecimento de quaisquer dúvidas. Contudo, a falta de informações sobre a amamentação pode ocasionar as fissuras mamilares e o ingurgitamento ${ }^{(15)}$. O estudo citado corrobora com os achados, pois a maioria das puérperas entrevistadas apresentaram como principais complicações mamárias as fissuras e ingurgitamento.

A literatura ${ }^{(6,16)}$ aponta os problemas mamários como principais fatores que levam ao desmame precoce, dentre eles, os traumas mamilares, fissuras e ingurgitamentos são os mais comuns.

A educação em saúde realizada pelo Projeto Consulta de Enfermagem no Pré-Natal e Pós-Parto tem o intuito de prevenir as complicações mamárias. Tendo em vista que as complicações mamárias quando instauradas são extremamente dolorosas, o enfermeiro deve intervir imediatamente frente ao 
problema causador da dor mamilar, promovendo assim a cicatrização das lesões ${ }^{(10)}$.

O Projeto Consulta de Enfermagem no Pré-Natal e Pós-Parto realiza suas ações educativas por meio de avaliação individualizada, distribuindo também panfletos que salientam a relevância do aleitamento materno e os principais cuidados a serem realizados com as mamas, para que não surjam as complicações mamárias.

\section{CONCLUSÃO}

O estudo apresentou um breve perfil sociodemográfico e obstétrico das puérperas, possibilitando melhor conhecimento da população atendida pelos enfermeiros, docentes e acadêmicos, permitindo assim potencializar a educação em saúde como estratégia de prevenção para problemas mamários que podem ser evitados.

Constatou-se a baixa adesão ao Programa Ministerial (42,9\%), dado preocupante quanto à eficiência da educação em saúde realizada pelos profissionais de saúde envolvidos na consulta do pré-natal. A adesão ao programa do pré-natal é fundamental para o binômio mãe/bebê, que visa também o controle de parâmetros e acompanhamento de indicadores em saúde no decorrer do ciclo gravídico-puerperal.

Atividades que tenham por objetivo a melhoria das ações educativas a puérpera fazem-se necessárias, fortalecendo a inter-relação com o enfermeiro como forma de melhorar a saúde física e mental da mãe/recém-nascido.

Foi possível apurar, a partir do levantamento de dados nas consultas de enfermagem neste estudo, que as principais complicações mamárias são as fissuras e o ingurgitamento, constatando-se que a educação em saúde oferecida no pré-natal e pós-parto advinda do Projeto Consulta de Enfermagem no Pré-Natal e Pós-Parto é fundamental para mãe/puérpera, visando prevenir essas complicações. A abordagem educativa de prover informações sobre o processo da lactação, a importância da livre demanda, estimulação da produção do leite, posições de amamentação, processo de ordenha, conservação e validade do leite materno, cuidados com as mamas, e outras ações voltadas para saúde da mãe e da criança, colaboram para promoção da saúde física e emocional materna, estimulando a prática da amamentação, conforme preconizado pelo Ministério da Saúde.

Este estudo possui limitação, por não ter pesquisado informações sobre a qualidade da educação em saúde realizada com as gestantes e puérperas pelos enfermeiros.

\section{REFERÊNCIAS}

1. Almeida MS, Silva IA. Necessidades de mulheres no puerpério imediato em uma maternidade pública de Salvador, Bahia, Brasil. Rev. esc. enferm. USP. [Internet] 2008; 42(2) [acesso em 09 jul 2015]. Disponível: http:// dx.doi.org/10.1590/S0080-62342008000200019.

2. de Abreu FCP, Fabbro MRC, Wernet M. Fatores que intervêm na amamentação exclusiva: revisão integrativa. Rev. Rene. [Internet] 2013; 14(3) [acesso em 15 jan 2015] Disponível: http://www.revistarene.ufc.br/revista/index. php/revista/article/view/697/pdf.

3. Ministério da Saúde (BR). Secretaria de Atenção à Saúde. Departamento de Atenção Básica. Saúde da criança: nutrição infantil: aleitamento materno e alimentação complementar. Brasília: Ministério da Saúde; 2009.

4. Kaufmann CC, Albernaz EP, da Silveira RB, da Silva MB, Mascarenhas MLW. Alimentação nos primeiros três meses de vida dos bebês de uma coorte na cidade de Pelotas, Rio Grande do Sul. Rev. paul. pediatr. [Internet] 2012; 30(2) [acesso em 17 mar 2016]. Disponível: http://dx.doi.org/10.1590/S0103-05822012000200002.

5. Olimpio DM, Kochinski E, Ravazzani EDA. Fatores que influenciam no aleitamento materno e desmame precoce em mães adolescentes e adultas. Cadernos da Escola de Saúde. [Internet] 2010; 1(3) [acesso em 17 mar 2016]. Disponível: http://revistas.unibrasil.com.br/cadernossaude/index.php/saude/article/view/59/59.

6. Roig AO, Martínez MR, García JC, Hoyos SP, Navidad GL, Álvarez JCF, et al. Fatores associados ao abandono do 
aleitamento materno durante os primeiros seis meses de vida. Rev. Latino-Am. Enfermagem. [Internet] 2010; 18(3) [acesso em 08 fev 2015]. Disponível: http://dx.doi.org/10.1590/S0104-11692010000300012.

7. Paraná. Secretaria de Estado da Saúde do Paraná (SESP). Superintendência de Atenção à Saúde. Linha Guia da Rede Mãe Paranaense. Curitiba (PR): SESP; 2013.

8. Ministério da Saúde (BR). Iniciativa Hospital Amigo da Criança: revista atualizada e ampliada para cuidado integrado. Fundo das Nações Unidas para a Infância. Organização Mundial da Saúde. Brasília: Editora do Ministério da Saúde; 2010.

9. Ministério da Saúde (BR). Secretária de Atenção a Saúde. Área Técnica de Saúde da Criança e Aleitamento Materno. Rede Amamenta Brasil: os primeiros passos (2007-2010). Brasília: Ministério da Saúde; 2011.

10. de Oliveira AP, Gavasso WC. A atuação do enfermeiro na promoção do aleitamento materno em unidades de estratégia saúde da família do município de Joaçaba, SC. U\&C - ACBS [Internet] 2012; 3(1) [acesso em 07 fev 2015]. Disponível: http://editora.unoesc.edu.br/index.php/acbs/rt/metadata/1296/pdf.

11. Ministério da Saúde (BR). Secretária de Atenção a Saúde. Departamento de Atenção Básica. Atenção ao prénatal de baixo risco. Brasília: Editora do Ministério da Saúde; 2012.

12. Demito MO, da Silva TC, Páschoa ARZ, Mathias TAF, Bercini LO. Orientações sobre amamentação na assistência pré-natal: uma revisão integrativa. Rev. Rene. [Internet] 2010; 11(n.esp) [acesso em 28 jul 2015]. Disponível: http:// www.revistarene.ufc.br/edicaoespecial/a25v11esp_n4.pdf.

13. de Souza VB, Roecker S, Marcon SS. Ações educativas durante a assistência pré-natal: percepção de gestantes atendidas na rede básica de Maringá-PR. Rev. Eletr. Enf. [Internet] 2011; 13(2) [acesso em 20 fev 2016]. Disponível: http://dx.doi.org/10.5216/ree.v13i2.10162.

14. de Oliveira MGOA, de Lira PIC, Batista Filho M, Lima MC. Fatores associados ao aleitamento materno em dois municípios com baixo índice de desenvolvimento humano no Nordeste do Brasil. Rev. bras. epidemiol. [Internet] 2013; 16(1) [acesso em 14 out 2015]. Disponível: http://dx.doi.org/10.1590/S1415-790X2013000100017.

15. Sanches MIC, Buccini GS, Gimeno SGA, Rosa TEC, Bonamigo AW. Fatores associados a interrupção do aleitamento materno exclusivo de lactentes nascidos com baixo peso assistidos na atenção básica. Cad. Saúde Pública. [Internet] 2011; 27(5) [acesso em 29 nov 2015]. Disponível: http://dx.doi.org/10.1590/S0102$311 X 2011000500013$.

16. Vieira GO, Martins CC, Vieira TO, de Oliveira NF, Silva LR. Fatores preditivos da interrupção do aleitamento materno exclusivo no primeiro mês de lactação. J. Pediatr. [Internet] 2010; 86(5) [acesso em 23 set 2015]. Disponível: http://dx.doi.org/10.1590/S0021-75572010000500015. 